Portland State University

PDXScholar

\title{
A Study of the Association Among the Diagnosis of Speech-Language Impairments and the Diagnoses of Learning Disabilities and/or Attention Deficit Hyperactivity Disorder
}

Pamela E. Cogswell

Portland State University

Follow this and additional works at: https://pdxscholar.library.pdx.edu/open_access_etds

Part of the Speech and Hearing Science Commons

Let us know how access to this document benefits you.

\section{Recommended Citation}

Cogswell, Pamela E., "A Study of the Association Among the Diagnosis of Speech-Language Impairments and the Diagnoses of Learning Disabilities and/or Attention Deficit Hyperactivity Disorder" (1992).

Dissertations and Theses. Paper 4222.

https://doi.org/10.15760/etd.6104

This Thesis is brought to you for free and open access. It has been accepted for inclusion in Dissertations and Theses by an authorized administrator of PDXScholar. Please contact us if we can make this document more accessible: pdxscholar@pdx.edu. 
AN ABSTRACT OF THE THESIS OF Pamela E. Cogswell for the Master of Science in Speech Communication: Speech and Hearing Science presented October 5, 1992.

Title: A Study of the Association Among the Diagnosis of Speech-Language Impairments and the Diagnoses of Learning Disabilities and/or Attention Deficit Hyperactivity Disorder.

APPROVED BY THE MEMBERS OF THE THESIS COMMITTEE:
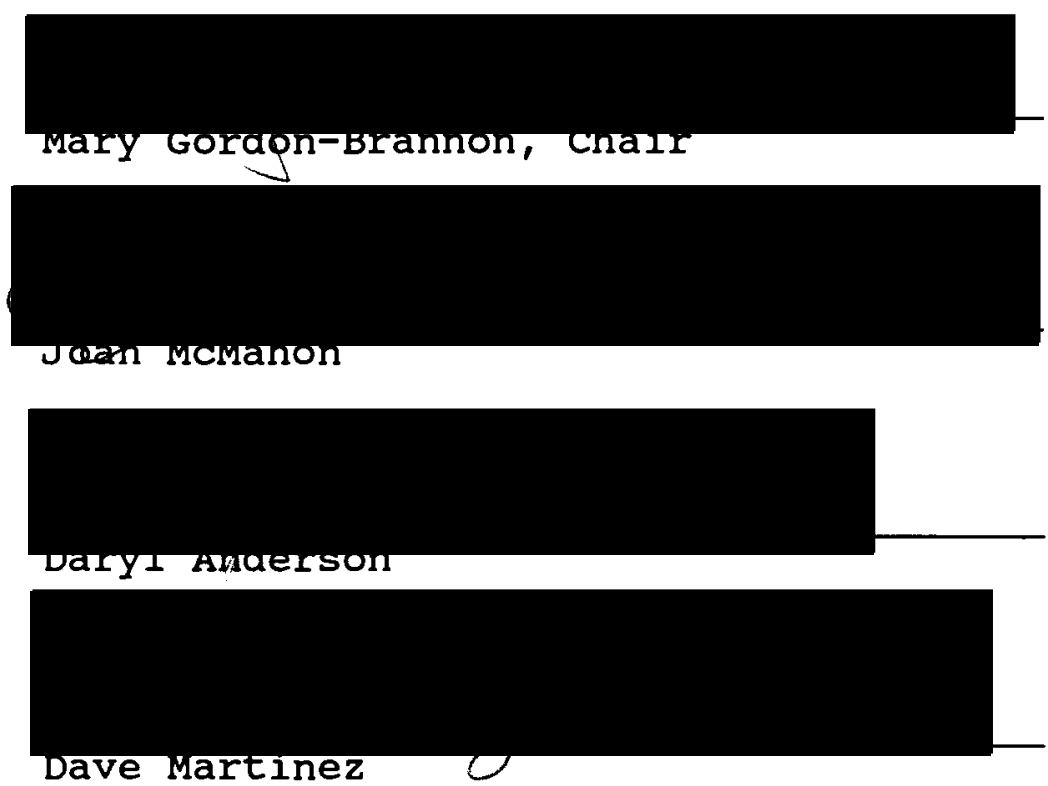

The purpose of this study was to determine if an association exists among the diagnosis of speech-language impairments (SLI) and the diagnoses of learning disabilities (LD) and/or attention deficit hyperactivity disorder (ADHD) 
in a school-aged population of children referred to a Learning Disorders Clinic (IDC) because of academic underachievement and/or behavior problems. The two research questions asked in this study are: (a) What percentage of students diagnosed with SLI have a concomitant diagnosis of LD and/or ADHD? and (b) Is there an association among the diagnosis of SLI and the diagnoses of LD and/or ADHD?

A sample of 94 subjects was obtained from review of 291 LDC records of children referred and diagnosed during the years 1989-1992. The subjects were grouped into eight categories by diagnosis, that is, (a) SLI, (b) SLI/LD, (c) SLI/ADHD, (d) SLI/LD/ADHD, (e) no diagnosis of SLI/LD/ADHD, (f) LD, (g) ADHD, and (h) LD/ADHD. The obtained chi square value was not statistically significant at a .05 alpha level. Thus, the null hypothesis: there will be no association among the diagnosis of SLI and the diagnoses of LD and/or ADHD, could not be rejected. In this sample, however, $85 \%$ of the children diagnosed with SLI had a concomitant diagnosis of $\mathrm{LD}$ and/or ADHD, and 708 with no SLI diagnosis were diagnosed with LD and/or ADHD.

The overlapping nature of the disorders of SLI, LD, and ADHD is noted. The definitions of SLI and LD demonstrate how enmeshed language and learning problems are. One inference from this study is that as children grow older, their language deficits are recognized in the context of a learning disorder. 


\title{
A STUDY OF THE ASSOCIATION AMONG THE DIAGNOSIS \\ OF SPEECH-LANGUAGE IMPAIRMENTS AND THE DIAGNOSES OF LEARNING DISABILITIES AND/OR \\ ATTENTION DEFICIT HYPERACTIVITY DISORDER
}

\author{
by
}

PAMELA E. COGSWELL

A thesis submitted in partial fulfillment of the requirements for the degree of

\author{
MASTER OF SCIENCE \\ in \\ SPEECH COMMUNICATION: \\ SPEECH AND HEARING SCIENCE
}

Portland State University

1992 
TO THE OFFICE OF GRADUATE STUDIES;

The members of the Committee approve the thesis of Pamela E. Cogswell presented October 5, 1992.

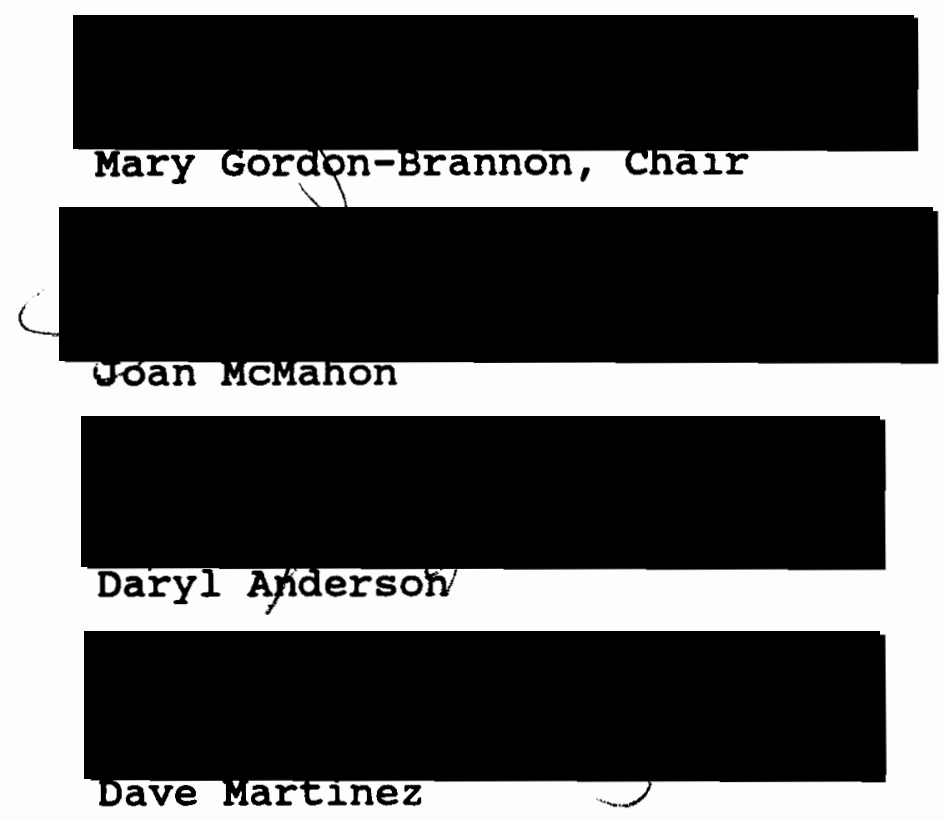

APPROVED :

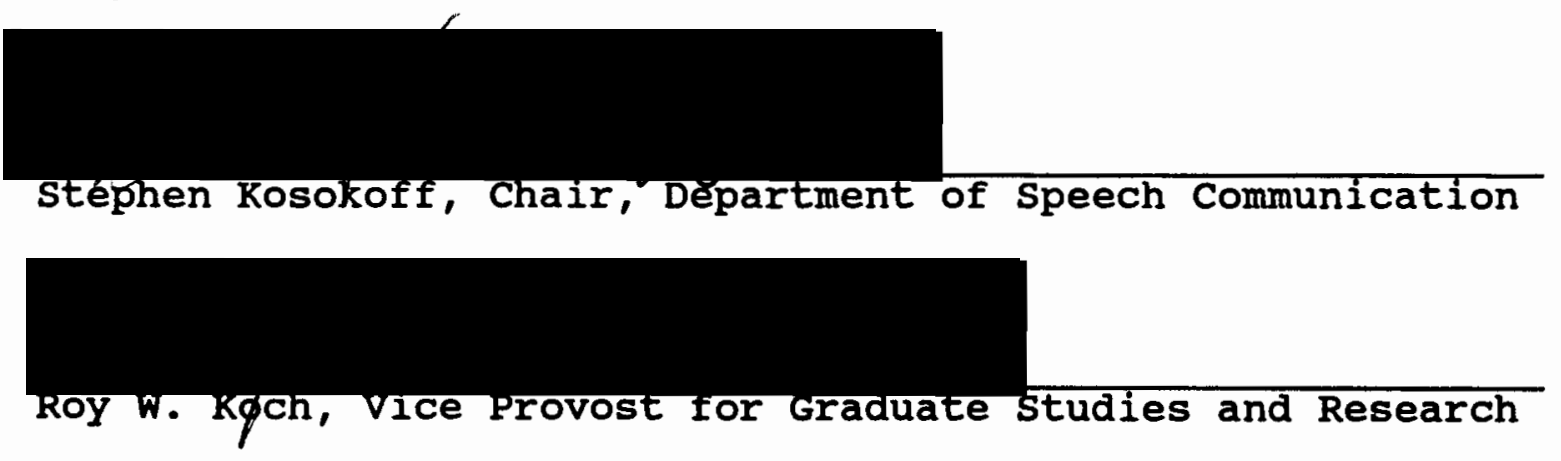




\section{ACKNOWLEDGEMENTS}

What started out nine years ago as an adventure in higher education has been achieved in this document. The Lord has worked through many people to help me obtain this goal. Some of you were models for me of what I could accomplish. There are many who were more direct in their support by helping me understand the significance of what I was accomplishing when I lost track. Then, there are those who helped me produce this final product by either direct and/or indirect instruction and guidance. And some of you did all of the above. To all of you who believed in me, thank you.

I am especially grateful to Mary Gordon-Brannon, my advisor and Thesis committee member, for her expertise and guidance and to the other Committee members; Joan McMahon, Daryl Anderson, and Dave Martinez for their contributions to this effort. I am also grateful to Dr. Darryn sikora, who manages the Learning Disorders Clinic at CDRC and whose support and feedback were invaluable. And a special thank you to Dr. Robert Casteel for his ongoing support and encouragement throughout my graduate program.

My deep appreciation is extended to Carol Ness, who proved that 15 minutes a days does a thesis make; to Teddy Lyons, the best devil's advocate there ever was; to Shawn 
Looney, whose support was and continues to be an inspiration to me; and to Gail Wild, without whose support this would not have been possible. My heartfelt appreciation is extended to the persons I am most grateful to for this accomplishment -- my children: Peter and Megan, for their sacrifices and unwavering support; and Dr. Helen G. Price, who helped pave a road and showed me the way. 
TABLE OF CONTENTS

PAGE

ACKNOWLEDGEMENTS • • • . . . . . . . . . . . . . ii

LIST OF TABLES . . . . . . . . . . . . . . . . vii

LIST OF FIGURES . . . . . . . . . . . . . . . . .viii

CHAPTER

I INTRODUCTION AND STATEMENT OF PURPOSE • • . . 1

Statement of Purpose . . . . . . . . 3

Definition of Terms . . . . . . . . 3

II REVIEW OF THE LITERATURE . . . . . . . . . 5

LD and ADHD . . . . . . . . . . . . 5

SLI and ADHD . . . . . . . . . . 9

SLI and LD . . . . . . . . . . . 11

Summary . . . . . . . . . . . 16

III METHODS . . . . . . . . . . . . . . 17

Subjects . . . . . . . . . . . . 17

Procedures . . . . . . . . . . 18

Assessment . . . . . . . . . . 18

File Review . . . . . . . . . . . 19

Data Measurement and Analysis . . 20

IV RESULTS AND DISCUSSION . . . . . . . . . 22

Results . . . . . . . . . . 22

Demographic Information . . . . 22

Research Question 1. . . . . . . 23

Research Question 2. . . . . . 25 
Discussion . . . . . . . . . . 26

$\mathrm{V}$

SUMMARY . . . . . . . . . . . . . . 33

Implications. . . . . . . . . . 35

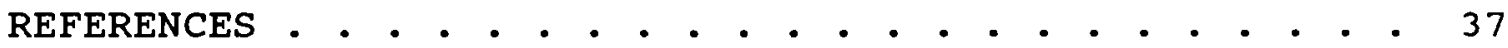

APPENDICES .

A DSM-IIIR CRITERIA FOR DIAGNOSIS OF ADHD . . . 40

B PATIENT POPUlation AT UAP OF OHSU . . . . . . 43

C DEMOGRAPHIC DATA UAP/OHSU . . . . . . . . . 45

D SELECTED ASSESSMENT MATERIALS USED BY

LEARNING DISORDERS CLINIC . . . . . . . . . . 47

E RESEARCH DATA FORM . . . . . . . . . . . 52

F SUMMARY OF DATA . . . . . . . . . . . . 54

G THE PERCENTAGES OF EXLUSIONARY FACTORS

IN THE 197 REFERRALS NOT ELIGIBLE FOR

THIS STUDY . . . . . . . . . . . . . . 59 


\section{LIST OF TABLES}

TABLE

PAGE

I Distribution of Speech and Language Impairments . . . . . . . . . . . . . 25 


\section{LIST OF FIGURES}

FIGURE

PAGE

1. $2 \times 2$ contingency Table Used for Chi Square Analysis . . . . . . . . . . 21

2. $2 \times 4$ contingency Table showing

Distribution of Subjects by Diagnosis . . . . 24

3. 2 X 2 Contingency with Collapsed

Distribution . . . . . . . . . . . . . 24 


\section{CHAPTER I}

\section{INTRODUCTION AND STATEMENT OF PURPOSE}

Language has been defined "as knowledge of a code for representing ideas about the world through a conventional system of arbitrary signals for communication" (Bloom \& Lahey, 1978, p. 23). The importance of the relationship of speech and language to thinking, learning, and communicating has long been established. The impact of a developmental speech and/or language delay or disorder can be far reaching.

Language is a distinctively human behavior, and language impairments may be the most pervasive problem for children with learning disabilities (Wiig and Semel, 1984). Research indicates an increased incidence of learning disabilities and behavior disorders in children with early speech-language impairments (Baker \& Cantwell, 1987; Baker, Cantwell \& Mattison, 1980; Botelho, 1986; Cantwell \& Baker 1977, 1985, 1991; Giddan, 1991; Wallach \& Liebergott, 1984). Eleven percent of the school-age population in this country is enrolled in special education (Heward \& Orlansky, 1988). The two largest categories of handicapping conditions are learning disabilities (ID) and speech and language impairments (SLI) (Digest of Education Statistics, 1988). 
A child referred for assessment and diagnosis of academic underachievement may present many overlapping symptoms, suggesting that language, learning, and behavior disorders may coexist. Cantwell and Baker's (1985, 1987, 1991) studies have investigated children with speechlanguage impairments. One of their studies examined the prevalence and types of psychiatric disorders and learning disabilities in children with SLI (Cantwell \& Baker, 1985). Attention deficit hyperactivity disorder (ADHD) was the most common psychiatric diagnosis of the children studied. The results further indicated that while ADHD is common in SLI children it is "most common in speech-language disordered children with LD" (Cantwell \& Baker, 1985, p. 91).

The original idea for this research evolved from the Cantwell \& Baker studies. The relationship between learning disabilities, behavior disorders, and speech-language impairments merits further exploration. In this study, the incidence of speech-language impairments in a sample of children diagnosed as learning disabled and/or attention deficit-hyperactive was investigated. At issue for school speech-language pathologists is whether children referred to the multidisciplinary education team due to concerns related to academic underachievement and/or behavior problems should routinely be examined by speech-language pathologists to determine the existence of speech-language impairment. 
STATEMENT OF PURPOSE

The purpose of this study was to examine the relationship among speech and language impairments (SLI) and learning disabilities (ID) and attention deficithyperactivity disorders (ADHD) in school-aged children. The focus of this research was to determine if a relationship existed among these variables. The questions this study sought to answer are:

1. What percentage of children diagnosed with SLI have a concomitant diagnosis of LD and/or ADHD?

2. Is there an association among the diagnosis of SLI and the diagnoses of LD and/or ADHD?

The null hypothesis resulting from these questions is: There will be no association among the diagnosis of SLI and the diagnoses of LD and/or ADHD.

\section{DEFINITION OF TERMS}

The following definitions were used for the execution of this study:

\section{Attention Deficit-Hyperactivity Disorder (ADHD) [aka}

Attention Deficit Disorder with Hyperactivity (ADDH)]: "The essential features of this disorder are developmentally inappropriate degrees of inattention, impulsiveness, and hyperactivity" (DSM-IIIR definition as cited by the American Psychiatric Association, 1987, p. 50). The DSM-IIIR 
diagnostic criteria are presented in Appendix A. The evolution of the term to describe this syndrome has included Attention Deficit Disorder (ADD) and ADD with and without hyperactivity. For this study, ADHD will be used to describe the syndrome with the features described in the foregoing definition.

Learning Disabilities (LD):

Specific learning disability means a disorder in one or more of the basic psychological processes involved in understanding or in using language, spoken or written, which may manifest itself in an imperfect ability to listen, think, speak, read, write, spell, or to do mathematical calculations. The term includes such conditions as perceptual handicaps, brain injury, minimal brain dysfunction, dyslexia and developmental aphasia. The term does not include children who have learning problems which are primarily the result of visual, hearing, or motor handicaps, or mental retardation, or emotional disturbance, or of environmental, cultural, or economic disadvantage (USOE, 1977, p. 65083, as cited by Mercer, KingSears, \& Mercer, 1990, p. 142).

Speech Lanquage Impaired (SLI):

An impairment in speech and/or language (including impaired articulation, stuttering, voice impairment, and a receptive or expressive verbal language handicap). In order to qualify for special education services under P.L. 94-142 in the category of "speech [language] impaired", the impairment must be sufficiently severe to adversely affect the individual's performance in the usual school program (Shafritz, Koeppe, \& Soper, 1988, p. 443). 


\section{CHAPTER II}

\section{REVIEW OF THE LITERATURE}

The importance of language to learning is demonstrated by the labels used to describe the academic problems of children, for example, language/learning disabilities, language-reading disorders, language disorders, and language disabilities (Wallach \& Liebergott, 1984). A delay or disorder in the development of language skills may result in behavioral problems as well. In studies of the prevalence of psychiatric and learning disabilities in children with speech-language impairments, ADHD has been found to be the most common behavior disorder (Baker et al., 1980; Cantwell \& Baker, 1985, 1991).

\section{LD AND ADHD}

The association between LD and ADHD has long been recognized. Children diagnosed ADHD are at risk for learning problems (Cantwell \& Baker, 1991). DSM-IIIR designates "academic underachievement" as an associated feature of ADHD. "School failure is the major complication" (American Psychiatric Association, 1987, p. 51).

In a review of the relationship between ADHD and LD, Keogh (1971) presented three hypotheses to explain the academic problems of hyperactive children:

(a) neurological 
academic problems of hyperactive children: (a) neurological impairment causes behavior and learning disability,

(b) hyperactivity causes attention problems which interfere with acquisition of information, and (c) impulsive behavior cases errors in decision-making.

A major problem for LD students is the inability to sustain attention (Dykman et al., 1983, as cited in Meents, 1989). When the syndrome of ADHD was first being diagnosed, the primary symptom was excessive motor activity. At that time, the hyperactivity was attributed to central nervous system dysfunction (Cantwell, \& Baker, 1991). The focus on etiology changed to describing behavior because "All hyperactive children are not brain damaged, and all children who are brain damaged are not hyperactive" (Birch, 1964; Birch, Thomas, \& Chess, 1964; Schrager, Lindy, Harrison, McDermott, \& Wilson, 1966, as cited by Keogh, 1971, p. 102). This new focus resulted in the primary symptom changing from "hyperactivity" to "a deficit in attention and concentration ability" (Cantwell \& Baker, 1991, p. 88).

Although it is generally accepted that many children with hyperactivity are poor students with learning problems, no one explanation of the relationship between ADHD and poor academic performance is generally accepted (Keogh, 1971). Throughout the literature, different explanations of the impact that hyperactivity and poor attention have on cognitive development have been proposed. Goldstein (1987) 
studied the effects of inattentiveness, hyperactivity, and aggressiveness observed in 7,119 children between 6 and 11 years of age on their later cognitive performance at 12 to 17 years of age. One-third of the original sample was involved in the second phase of the study, which determined that hyperactivity and aggressivity did not play an important role in cognitive development; however, inattentiveness was related to cognitive performance. The explanation of the results was acquiring academic knowledge is difficult without attending and that learning advanced skills is more difficult if basic skills are not learned in early development (Goldstein, 1987).

Environment, caregiver, and types of activities influence the behavior of a child who is hyperactive. Because of these influences, school performance is inconsistent (Guevremont, DuPaul, \& Barkley, 1990). Cunningham and Barkley (1978) suggested "hyperactive behavior may be the result rather than the cause of the child's academic difficulties" (p. 16).

Cantwell and Satterfield (1978) suggested that lower ability level is not an acceptable explanation for academic underachievement by children who are hyperactive. They compared school performance of 94 children diagnosed "hyperactive" using purely behavioral criteria with 54 "normal" public school children. Criteria for diagnosis of 
hyperactivity was (a) "excessive general motor activity or motor restlessness inappropriate for the child's age," (b) "difficulty sustaining attention," and (c) "impulsive behavior," (Cantwell \& Satterfield, 1978, p. 168). Poor performance in reading, math, and spelling was defined "as performing at a grade level below that predicted for an average child of the same chronological age and WISC full scale IQ" (p. 169). The results indicated that threequarters of the hyperactive students were behind to some degree in each of the three subject areas. Cantwell and Satterfield concluded that lower ability level does not explain the learning problems of hyperactive children because their definition of "academic achievement" took into account each child's chronological age, and IQ was not less than 85 .

stimulant drugs are sometimes used to reduce the symptoms of hyperactivity which are seen as interfering with academic performance, that is, impulsivity and lack of concentration (Cunningham \& Barkley, 1978). The fact that medical and behavioral intervention does not often result in improved academic performance leads some researchers to believe that ADHD evolves form learning disabilities (McGee \& Share, 1988). Cunningham and Barkley (1978) reviewed over 120 drug studies and concluded that stimulant drugs have little or not impact on academic achievement in hyperactive children because drug intervention does not address the 
underlying academic problems which cause negative classroom experiences and off-task behavior. They concluded that successful academic achievement eliminated ADHD in certain students. Although there does not appear to be a clearly defined relationship between $L D$ and $A D H D$, deficits in attention and concentration are behaviors presented by children diagnosed LD and ADHD. One study showed that the impact of hyperactivity did not interfere significantly in cognitive development; however, inattentiveness was a related interference (Goldstein, 1987). An explanation of this interference was that learning advanced skills is more difficult if basic skills are not learned in early development. Inattentiveness, then, may also have implications for delayed language development, as well.

\section{SLI AND ADHD}

If language is the medium in which learning occurs, then what connection exists between ADHD and language development? The following studies have indicated there is an association between language impairments and ADHD.

Children with speech disorders and speech-language disorders were rated by parents and teachers for behavioral problems in a study conducted by Baker et al. (1980). Ninety-nine children between the ages 3:6 and 11:6 were included in the study. Based on speech and language 
testing, 46 children were placed in the speech-only group and 53 children were placed in the speech-language group. Standardized questionnaires were distributed to parents and teachers to determine the prevalence of behavioral problems. "Both parents and teachers rated the SLI children as significantly more restless, excitable, or impulsive, fidgety, and easily distracted than the pure speech group," (Baker, et al., 1980, p. 249). One of the main distinguishing behaviors of the SLI group which was different from the speech-only group was hyperactivity.

Cantwell and Baker (1985) further examined the association between psychological and academic problems in children with speech-language disorders. Over a 3-year period, 600 children, ranging in age from 1:7 to 15:9 were evaluated at a speech and hearing clinic in greater Los Angeles. Of the children included in the study, $92 \%$ had a speech production disorder, and $66 \%$ were diagnosed with a language delay or disorder. Of the total sample, 237 present receptive language problems (mean age $=5: 5,70 \%$ were males) and 363 presented expressive language problems (mean age $=5: 2,70 \%$ were males). The most common behavior disorder among the subjects was ADHD. Cantwell and Baker estimated that $5 \%$ of school-aged boys present behaviors in keeping with a diagnosis of ADHD. Based on the results that $17 \%$ of the SLI subjects were diagnosed ADHD, they concluded that children with SLI are at risk for learning disorders. 
Three hundred children from the original study of 600 were followed up 4 to 5 years lager (mean age $=9: 1$ years). of the 300 children, $66 \%$ were considered to psychiatrically ill, with ADHD being the most common diagnosis (37\%) of the follow-up sample. Ninety-one of the 300 subjects were diagnosed with LD, and of these, 53\% had a diagnosis of ADHD, which was the most common diagnosis in the LD group. Although Cantwell and Baker (1991) do not address the issue of the numbers of subjects who continued to be SLI, it is clear from these studies that children with SLI are at risk for learning and behavioral problems associated with ADHD. Botelho (1986) compared the behavior problems of SLI children with normal children. Her study showed few differences between the SLI and normal subjects; however, when the SKI group was divided into speech and language groups, the children with language impairments showed significantly more behavior problems. The foregoing studies have indicated that the inattentive behavior included in ADHD and associated with LD may also be associated with SLI.

\section{SLI AND LD}

Learning disabilities can be seen as a continuation of developmental language delays or disorders (Wallach \& Liebergott, 1984). In their study of the incidence of communication disorders in students with learning 
disabilities, Gibbs \& Cooper (1989) determined the prevalence of articulation, fluency, voice, language, and hearing disorders in LD students between the ages of 8 and 12. At least one or more of the disorders assessed were present in $96.2 \%$ (233) of the 242 children demonstrating LD. The incidence of disorders ranged from $90.5 \%$ with mild to moderate language disorders to $1.2 \%$ with fluency disorders.

In the general school-aged population, $4 \%$ to $6 \%$ are expected to have articulation disorders, but in one study 23. $1 \%$ of the students with LD had articulation disorders (Healey, Ackerman, Chappell, Perrin, \& Stormer, 1981, as cited by Gibbs \& Cooper, 1989). The significance of poor articulation to reading will be reviewed later. The Healey et al. study indicated that children who are diagnosed with LD do not outgrow communication disorders as they mature. The most prevalent problem for children with learning disabilities is difficulty in reading (Kuder, 1991). The three language skill areas which appear to be prerequisites for learning to read are phonology, syntax, and discourse. Kuder examined the possibility that some students with LD "have underlying information-processing disabilities" (p. 124) that preclude them from learning to read because of deficits in the three language prerequisites. In the Kuder study, 26 inner city students with LD who had been diagnosed as "perceptually impaired" were administered the Woodcock Reading Mastery Test (WRAT), the PPVT-R, and the Word 
Discrimination and sentence Imitation subtests of the TOLD-P. The PPVT-R scores correlated with the word comprehension score of the WRAT at a .05 level of significance. The Word Discrimination and Sentence Imitation subtests were significantly related to overall reading achievement ( $p .<.01)$. This study concluded that "word attack sills are related to phonological abilities, and word comprehension is related to syntactic knowledge" (Kuder, 1991, p. 126).

Deficits in processing the phonological aspects of language were found in students between the ages of 12:7 and 15:9 whose reading and spelling performance was at least 2 years behind (Catts, 1986). Catts used three speech production tasks: (a) naming pictured objects, (b) repetition of multisyllabic words, and (c) repetition of phrases. The reading disordered subjects made significantly more errors in producing multisyllabic words and short phrases than the control subjects. The LD students wit the poorest reading scores made the most errors on the speech production tasks and subjects with a moderate reading disability made fewer errors.

Catts (1985) speculated that errors in speech production may be the result of deficits in the formation of phonological memory codes which influence the motor programs for speech. What may appear to be a semantic deficit when 
poor readers have word retrieval problems may actually be a deficit in storing information about the phonological aspects of words (Liberman \& Shankweiler, 1985).

Liberman and Shankweiler (1985) looked at the difficulties poor readers have in reading words, in naming, and in sentence comprehension. It appeared that the connection between speaking and writing is understanding that words have parts (i.e., phonemes, syllables, and morphemes). They concluded that what may appear to be a semantic deficit when poor readers have word retrieval problems may instead be a deficit in storing information about the phonological aspects of words. They further concluded that sentence understanding and comprehension is compromised due to short term memory inefficiency caused by errors in word recognition due to phonological deficits.

Van der Wissel (1988) tested the theory that children with learning problems are not troubled by poor receptive vocabularies, but they are troubled by problems with their abilities to produce words, that is, speed of naming and verbal expression. He concluded that "Hampered word production, not poor vocabulary, is characteristic of problem learners" (p. 518). Specifically, children with learning problems may be disabled by not being able to label quickly and/or describe word meanings.

Another hypothesis which has been studied is that children with deficits in narrative skills, relative to 
other language skills, are at risk for general academic problems, especially in reading comprehension (Feagans \& Appelbaum, 1986). Feagans and Appelbaum examined the syntactic, semantic, and discourse or narrative language skills of students experiencing LD. They concluded that a critical skill for children with $L D$ to perform academically is the ability to understand and paraphrase narratives. They further suggested that discourse skills may be more important than vocabulary and syntax skills.

children with SLI are at risk for academic problems. As Liberman and Shankweiler (1985) stated, "...learning to read and write depends in large part on special languagerelated skills that go beyond the primary abilities required in producing and understanding speech" (p.8). They determined that phonological, syntactical, and narrative abilities were necessary for learning to read and write. The studies cited in this review hypothesized that poor word attack skills, word retrieval, and sentence comprehension may be the result of short term memory deficits for storing information about the phonological aspects of words. In assessing the impact of SLI on children, there also appeared to be a relationship between language deficits and learning and/or behavior problems. 
Language impairments are a pervasive problem for children with LD and behavior problems. Children referred for assessment and diagnosis of learning problems may present behaviors that indicate language, learning, and behavior problems coexist. Cantwell and Baker (1985, 1991) concluded there is an increased incidence of LD and behavior problems in children with SLI. They further concluded that there is a higher incidence of ADHD in children diagnosed as both SLI and LD. 
CHAPTER III

METHODS

SUBJECTS

The subjects were selected from children assessed and diagnosed at the Learning Disorders Clinic (IDC) at the University Affiliated Program (UAP) of oregon Health Sciences University (OHSU). The primary goals of the clinic are to answer research questions about school learning problems in children and to provide training for inservice and pre-service professionals and parents involved with children's underachievement in school (University Affiliated Program, 1985).

Children who were assessed at the LDC during the years 1989-1992 and who met the criteria for selection were included in this study. The subjects were grouped into eight categories by diagnosis: (a) SLI, (b) SLI/LD, (c) SLI/ADHD, (d) SLI/LD/ADHD, (e) no diagnosis of SLI/LD/ADHD and the isolated diagnoses of (f) LD, (g) ADHD, and (h) LD/ADHD.

Criteria for inclusion in the study included:

1. The primary reason for referral was academic underachievement and/or behavior problems.

2. Age at the time of assessment was between the ages 
of $7: 0$ and $15: 11$.

3. Intelligence was normal (full scale IQ not less than 85) as determined by a standardized instrument.

4. Hearing was within normal limits for speech reception as determined by the IDC evaluation or from audiological examination done no more than 6 months prior to the IDC evaluation.

5. Birth was full term with no known chronic health or physical handicaps (such as blindness, PKU, or cerebral palsy) at the time of assessment.

The children referred to the LDC were from the Northwest and represented a cross-section of sex and race, although socioeconomic status (SES) was not among a criteria for inclusion in this study. Appendices $B$ and $C$ present Tables which describe the patient population at the UAP and the age and ethnicity of the population from which the sample was drawn.

\section{PROCEDURES}

\section{Assessment}

An interdisciplinary team assessed and diagnosed children referred to the LDC. The team was composed of staff from pediatrics, psychology, social work, special education, and speech-language pathology. An audiological exam was also administered to each child referred to the 
clinic unless a current record of such an exam was made available at the time of referral. The diagnoses are made by data and observation. Appendix D lists selected assessment materials used by the clinic team members. The instruments used were chosen based on the referral questions for each child. A significant aptitude-achievement discrepancy ( 1 SD) was a requirement for a diagnosis of LD. Children diagnosed with a language impairment also had to present a significant discrepancy (1 SD) between cognitive ability and language performance. The methods for assessment of ADHD involved interview, standardized child behavior rating scales, laboratory measures, and direct observation. The case manager coordinated the examination of the child being assessed and complied a synthesized report which recorded the team's assessment results, diagnoses, and recommendations for intervention.

\section{File Review}

The data obtained for this study were acquired by this investigator through review of 291 files on children evaluated at the LDC during the years 1989-1992. After determining which children met eligibility criteria for this study, the reports resulting from each subject's assessment were examined to determine into which diagnostic categories each subject was placed (SLI, LD, and/or ADHD). Appendix E shows the Research Data Form used for each file review. It 
was determined during the file review that subjects diagnosed Severely Emotionally Disturbed and subjects who had been severely sexually abused (e.g., from 18 months to 5 years) would not be included in this study.

A summary of the information gathered on each subject was recorded on the Summary of Research Data (Appendix F). This summary noted the sex; age at time of evaluation; reason for referral; IQ score; whether the subject was SLI, LD, and/or ADHD; the type of SLI; if the subject had a known diagnosis of SLI, LD, and/or ADHD (preexisting condition); and comments noting specific characteristics of the learning disabilities and behavior of the subject. After the data on each subject were recorded, the subjects were grouped into eight categories: (a) SLI, (b) SLI/LD, (c) SLI/ADHD, SLI/LD/ADHD, (e) no diagnosis of SLI/LD/ADHD, and the isolated diagnoses of (f) LD, (g) ADHD, and (h) LD/ADHD. These categories were then tallied.

\section{Data Measurement and Analysis}

Descriptive analysis consisted of first determining the number and percentages of subjects falling into each group. In order to show whether or not a relationship existed among the groups, the Chi square statistic was applied because of the categorical nature of the variables (Jaeger, 1990). The Chi square compare the observed frequencies with the expected frequencies (Twaite \& Monreod, 1979). The more 
closely the observed and expected frequencies are to one another, the less the variables are associated to one another. For this study, in order to reject the null hypothesis in favor of the alternative hypothesis that SLI, LD, and ADHD are statistically dependent, Chi square must be greater than the critical value at a .05 alpha level. The initial design for analysis of the data was to use a $2 \times 4$ contingency table, however, there were not enough subjects in all of the categories, and the distribution of the sample would have skewed the Chi square test. Therefore, a $2 \times 2$ contingency table was used which collapsed the groups into (a) SLI, (b) no SLI, (c) no LD/ADHD, and (d) LD/ADHD (Figure 1). The predicated result was that there is an association between SLI, and LD, and/or ADHD.

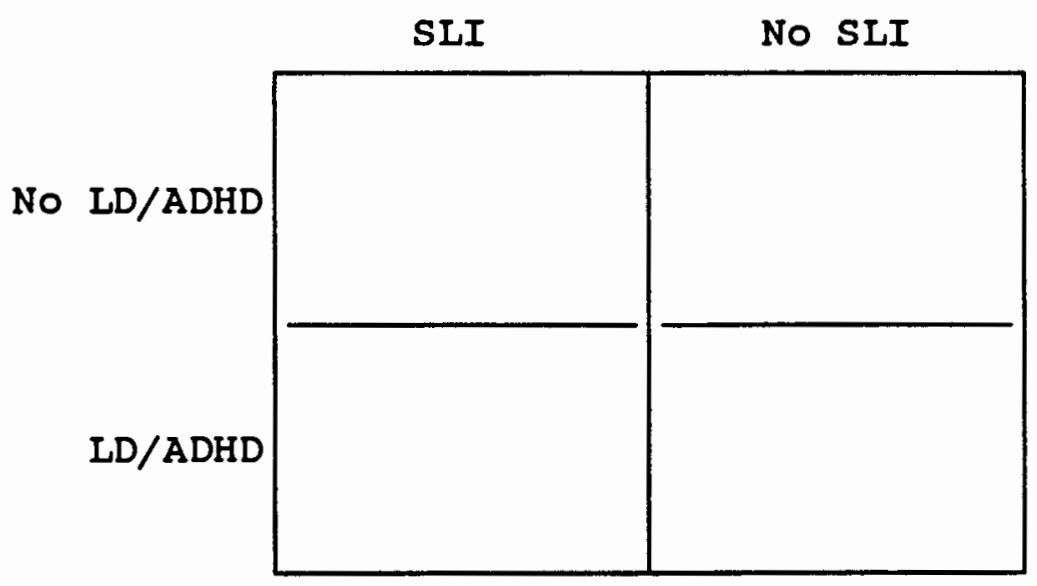

Figure 1. $2 \times 2$ contingency table used for $\mathrm{Chi}$ square analysis 


\section{CHAPTER IV}

\section{RESULTS AND DISCUSSION}

\section{RESULTS}

\section{Demographic Information}

The 94 subjects were obtained from review of 291 IDC records of children referred and diagnosed during the years 1989-1992. Appendix $G$ summaries the exclusionary factors pertaining to those children not meeting eligibility criteria, and Appendix $\mathrm{F}$ is a summary of the research data collected on each subject.

In this sample, $71(76 \%)$ subjects were males and 23 (24\%) were females. Almost half (48\%) of the children were referred solely because of concerns related to academic underachievement, while $33 \%$ had coexisting concerns such as behavior or ADHD, with $19 \%$ being referred solely for problem behavior or concerns related to ADHD. The mean age of the boys was 10:1, and the mean age of the girls was 10:5 at the time of referral. The mean IQ of boys and girls based on 85 subjects ( 9 of the subjects' IQ's were reported as "average or above average" with no quantitative data) was 101 with boys averaging 101 and the girls averaging 99. 
Research Question 1

The first research question asked was: What percentage of children diagnosed with SLI have a concomitant diagnosis of LD and/or ADHD? Figure 2 shows the distribution by diagnosis of the children who made up the sample for this study. In this sample, $85 \%$ of the children diagnosed with SLI had a concomitant diagnosis of LD and/or ADHD, leaving $15 \%$ with an isolated diagnosis of SLI; and $70 \%$ of the children with no SLI were diagnosed with ID and/or ADHD, leaving 308 of the sample with no diagnosis meeting the criteria for this study (Figure 3). These results provide evidence in favor of the alternative hypothesis: there is an association among the diagnosis of SLI and the diagnoses of LD and/ADHD. The largest diagnostic category was LD which contained 34 subjects $(36 \%)$ and the smallest diagnostic category was SLI/ADHD which contained 2 subjects (2\%). The second largest group was 20 subjects with no diagnosis of SLI, LD or ADHD. Only 68 of the sample was diagnosed with a combined diagnosis of SLI, LD and ADHD, while $9 \%$ were diagnosed with only ADHD. Of the isolated ADHD diagnoses, 8 (38\%) of the 21 subjects had a preexisting diagnosis of ADHD.

Table I shows the types of SII which were distributed in this sample. Among these, $37 \%$ were preexisting conditions in which the child's SLI had been identified prior to being seen in the IDC. Among the subjects 
diagnosed with LD, $31 \%$ had a concomitant diagnosis of SII. In the SII/LD group, $27 \%$ had a diagnosis of SII at the time of referral.

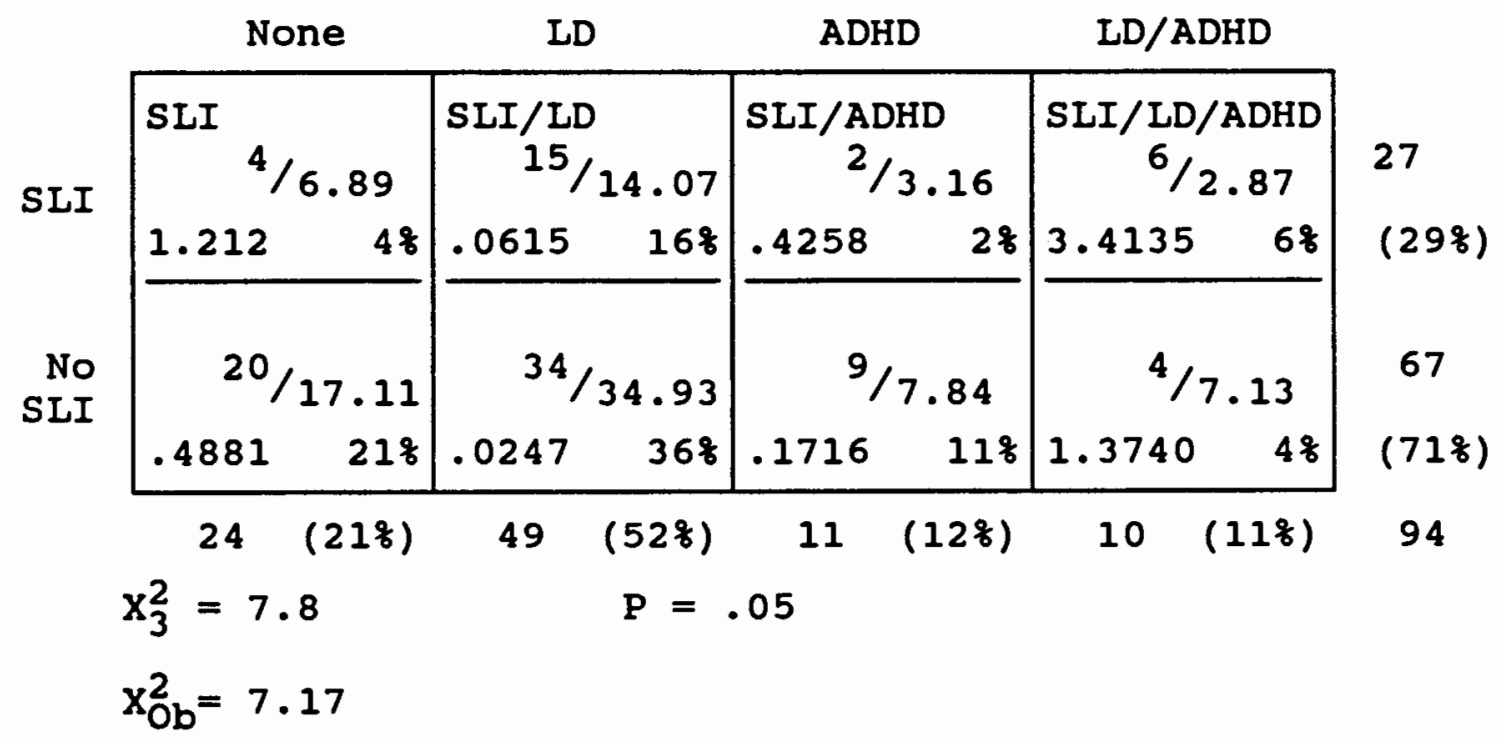

Figure 2. $2 \times 4$ contingency table showing distribution of subjects by diagnosis.

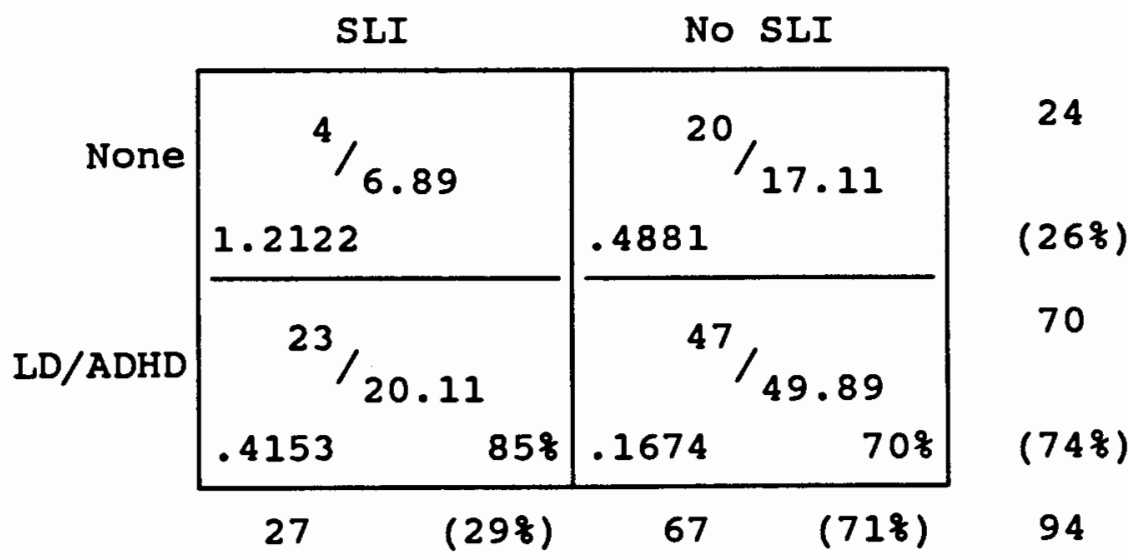

$$
\begin{array}{ll}
\mathrm{x}_{1}^{2}=3.8 & \mathrm{P}=.05 \\
\mathrm{x}_{\mathrm{Ob}}^{2}=2.28 &
\end{array}
$$

Figure 3. $2 \times 2$ contingency table with collapsed distribution. 
TABLE I

DISTRIBUTION OF SPEECH-LANGUAGE IMPAIRMENTS

\begin{tabular}{|c|c|c|}
\hline Articulation & $\mathrm{XXXX}$ & $(15 \%)$ \\
\hline Expressive Language & $x x x$ & $(118)$ \\
\hline Receptive Language & $\mathrm{XXXX}$ & (15\%) \\
\hline $\begin{array}{l}\text { Expressive/Receptive } \\
\text { Language }\end{array}$ & $\operatorname{xxx} \times x \times x \times x \times x$ & $(418)$ \\
\hline $\begin{array}{l}\text { Articulation/Expressive/ } \\
\text { Receptive Language }\end{array}$ & $\mathrm{xxXX}$ & $(15 \%)$ \\
\hline $\begin{array}{l}\text { Articulation/Expressive } \\
\text { Language }\end{array}$ & $x$ & (3\%) \\
\hline
\end{tabular}

New Diagnosis: $17(63 \%)$ Preexisting Diagnosis: 10 (37\%)

Research Question 2

The second research question asked was: Is there an association among the diagnosis of SLI and the diagnoses of LD and/or ADHD? Initially the subjects were grouped into eight categories by diagnosis. The dependence of the groups was tested for significance by means of a Chi square test of independence. In a $2 \times 4$ contingency table (figure 2) two of the cells did not have a large enough number to apply the Chi square test; therefore, a $2 \times 2$ table was used to apply the Chi square test (Figure 3). The obtained Chi square value of 2.28 was not statistically significant at the .05 
level. The magnitude of the difference between the observed and expected frequencies is not great enough to allow rejection of the null hypothesis: there is no association among the diagnosis of SLI and the diagnoses of LD and/or ADHD. However, the results do suggest an association because of those subjects diagnosed with SLI, $85 \%$ had a coexisting diagnosis of $L D$ and/or ADHD; whereas, only $70 \%$ of the subjects without a diagnosis of SLI had diagnoses of LD and/or ADHD.

\section{DISCUSSION}

The purpose of this study was to determine if an association exists among the diagnosis of SLI and the diagnoses of LD and/or ADHD in a school-aged sample of children referred to the LDC because of academic underachievement and/or behavior problems. The expected results were that there would be an association; however, a dependence was not shown using a Chi square test for independence at a .05 confidence level.

The inception of the research questions asked here was Cantwell and Baker's $(1985,1991)$ research into the psychiatric and learning disabilities in children with SLI. Their sample was obtained from children referred to a community speech and hearing clinic in the greater Los Angeles area. The initial results of their two-part study showed ADHD to be the most common diagnosis (19\%) in those 
subjects (50\%) with a psychiatric diagnosis. Forty-two of those subjects diagnosed ADHD were identified as LD. In the follow-up study, 91 of the 300 subjects were diagnosed LD, and $53 \%$ of that group were also diagnosed ADHD (Cantwell \& Baker, 1985, 1991). They concluded, therefore, that children with SLI and LD are at risk for behavioral problems associated with ADHD. These results show the overlapping nature of the disorders. If learning disabilities are a continuation of developmental language delays or disorders (Wallach \& Liebergott, 1984), would SLI be a prerequisite for ADHD?

Although an association among SLI, LD, and/Or ADHD cannot be statistically shown, this study does support the Cantwell \& Baker $(1985,1991)$ results. This research was conducted on a sample population of school-aged children who were experiencing learning and/or behavior problems either with or without concerns related to ADHD. Although this research sought to show the same results as the cantwell \& Baker studies showed, there are three main difference between the design of these two studies: (a) the nature of the sample populations, (b) the ages of the subjects, and (c) the control for IQ.

Cantwell \& Baker's (1985, 1987, 1991) studies are comprised of children who were referred for assessment of SLI, and this study is comprised of children who were 
referred for assessment of academic and/or behavior problems. The main difference between this study and the Cantwell and Baker studies is their studies were conducted proactively, as they identified children with SLI and examined what psychiatric and learning disabilities existed or developed; whereas, this study was conducted retroactively, as the investigator examined children referred for learning and/or behavior problems to determine if speech-language impairments were or would be present. Although the mean age of their original sample of 600 was $5: 6$, the majority of their subjects were in a preschool age range with a median age of 4:9 (Cantwell \& Baker, 1985). The eligibility criteria for this study required that the subjects be school-aged between 7:0 and 15:11. The mean and median age of this sample was 10:2. The lower incidence of speech production disorders in this study may be attributed to the age of the subjects. Of the $29 \%$ of the subjects with a diagnosis of SLI, $15 \%$ had an articulation disorder, $18 \%$ had a combination articulation and expressive and/or receptive language disorder, and $67 \%$ had expressive and/or receptive language disorders. The incidence of SLI in this sample is higher than would be expected in the general school-aged population, which is another indication of the association among SLI and LD and/Or ADHD.

Another control implemented in selection of subjects for this study was that cognitive ability be in the average 
range (IQ at least 85 ). The subjects in the Cantwell \& Baker (1985) study were administered IQ tests; however, they did not use cognitive function as an exclusionary factor. This is an important distinction because of the association between speech and language development and mental retardation (Bloom \& Lahey, 1978). The incidence of mental retardation in their study was $6 \%$ (Cantwell \& Baker, 1985). A follow-up to this study which includes subjects with IQ's of less than 85 may reveal a higher incidence of the combined diagnoses of SLI, LD, and/or ADHD.

Only 4 (4\%) of the subjects in this study had an isolated diagnosis of SLI, and 20 subjects had no diagnosis at all. Of the subjects diagnosed with SLI, 858 had a coexisting diagnosis of $\mathrm{LD}$ and/or ADHD. Of those subjects with no SLI, $70 \%$ were diagnosed with LD and/or ADHD. The foregoing percentages provide evidence to support the association among these three diagnoses.

In summary, in a study of the psychiatric and learning disorders of children referred for assessment of SLI, Cantwell \& Baker $(1985,1991)$ found an association among SLI, LD, and ADHD. The implications of that association are open to interpretation as researchers study whether ADHD is a cause or effect of SLI and/or LD (McGee \& Share, 1988). In this study of a sample of school-aged children referred for academic underachievement and/or behavior problems, 
there is evidence that children with SLI have more combined diagnoses of ID and/or ADHD, however this association cannot be statistically shown. The nature of the samples appears to dictate the outcome of both studies.

It is important to remember the definition used for SLI in this study:

In order to qualify for special education services under P.L. 94-142 in the category of "speech [language] impaired", the impairment must be sufficiently severe to adversely affect the individual's performance in the usual school program (Shafritz, Koeppe, \& Soper, 1988, p. 443).

In this study, eligibility as language disordered was contingent on standardized testing which reflected a discrepancy of at least 1 SD between language ability and cognition. Formal and informal analysis of the subject's spontaneous speech was also done. In Cantwell \& Baker's (1985) study, children were diagnosed with an "expressive language deficit" (p. 34) "if they scored below the 20 th percentile, or 2 SD below the mean, or 1 year below chronological age level" ( 6 months below chronological age level for pragmatic deficits analyzed during a language sample) (p. 34). Cantwell \& Baker's criteria for a "language processing deficit" were scoring

(a) more than 1 year below their chronological age level on the Memory for Sentences Test (Spencer, 1958), (b) below 'adequate' for their age levels on the Auditory Discrimination Test (Wepman, 1973), or (c) more than seven points below the scaled score norm on the ITPA subtests (Kirk, McCarthy, \& Kirk, 1968) (p. 36). 
Another consideration in discussing this study is the definition of "learning disability" which contains a large element of language skill, including listening skills. Reynolds and Fletcher-Janzen (1990) targeted disorders in "the psychological processes of attention, memory, perceptual ability, thinking, or oral language" as basic components in identifying persons as ID (p. 626). Language and learning problems thus become enmeshed. An example of this enmeshment is the language skill prerequisites Kuder (1991) identified for learning to read: phonology, syntax, and discourse. Feagans and Appelbaum (1986) also proposed that a critical skill for children with ID to perform academically is understanding and paraphrasing narratives which are discourse skills.

Mercer, King-Sears, and Mercer (1990) surveyed 51 state Departments of Education to determine their definitions of learning disabilities and "identification criteria and operationalization procedures" (p. 141), and they compared the results to a similar survey conducted in 1985. They reported that 49 states included 'language disorders' in "their definitions and/or criteria" (p. 146). of particular note was the increase from 148 to 808 of the states which added a language element to their criteria. They suggested that language disorders are being set apart from the "traditional process component which emphasizes perceptualmotor and modality deficits" (p. 146). One could infer from 
the findings of this study that as children grow older, their language deficits are recognized in the context of a learning disorder. This inference is further documented by the American Speech-Language Hearing Association's summary of the Thirteenth Annual Report to Congress on the Implementation of The Individuals with Disabilities Education Act made by the U.S. Department of Education in 1991. The summary reported that there has been an increase in the number of students with LD and a decrease in the number students with SLI (ASHA, 1991). One of the explanations of this decline was a movement in the direction of students with SLI being identified LD.

For the speech-language pathologist (SLP) in the schools, the results of this study support the need for the SLP to be a member of the multidisciplinary education team (MDT). As an adjunct to special education, children with academic and behavior problems are referred to the MDT to determine the most appropriate intervention. Although children with LD/ADHD appear to be more likely than the general school population to have SLI, routine examinations for SLI of all children referred for LD do not appear to be justified. Additionally, SLP's who work with students in preschool and elementary settings are in a good position to monitor their caseload for learning and/or behavior problems which may interfere with academic progress. 


\section{CHAPTER V}

\section{SUMMARY}

The purpose of this study was to determine if an association exists among the diagnosis of SLI and the diagnoses of $L D$ and/or ADHD in a school-aged population of children referred because of academic underachievement and/or behavior problems. Review of the literature suggested a relationship between LD and ADHD, although cause and effect have not been determined. Additionally, wallach and Liebergott (1984) suggested that ID can be seen as a continuation of developmental language delays or disorders.

Cantwell and Baker's (1985) study of the psychiatric and learning disabilities in children with speech and language deficits was the impetus for this research. They concluded that children with SLI and LD are at risk for behavioral problems associated with ADHD. This study asked two questions: (1) What percentage of students diagnosed with SLI have a concomitant diagnosis of LD and/or ADHD? and (2) Is there an association among the diagnosis of SLI and the diagnoses of LD and/or ADHD?

The sample for this research was comprised of 94 subjects who were obtained from review of 291 LDC records of children referred and diagnosed during the years 1989-1992. The subjects were grouped into eight categories by 
diagnosis, that is (a) SLI, (b) SLI/LD, (c) SLI/ADHD,

(d) SLI/LD/ADHD, (e) no diagnosis of SLI/LD/ADHD, (f) LD,

(g) ADHD, and (h) LD/ADHD. In this sample, 858 of the children diagnosed with SLI had a concomitant diagnosis of LD and/or ADHD, and 708 with no SLI diagnosis were diagnosed LD and/or ADHD. These results provide evidence to support an association among the diagnoses. The obtained Chi square value was not statistically significant at a .05 alpha level. Thus, the null hypothesis could not be rejected. A study done similar to this study without the control for IQ may show the association statistically, as more SLI are present in children with lower cognitive ability.

The main difference between this study and the Cantwell and Baker $(1985,1991)$ study is their study was proactive, and this study was retroactive. Three important differences between the designs of this study and the Cantwell \& Baker study are described: (a) the nature of the samples, (b) the ages of the subjects, and (c) the control for IQ. It is suggested that the nature of the samples appears to dictate the outcome of both studies.

The overlapping nature of the disorders of SLI, LD, and ADHD is notable. The definitions of SLI and LD demonstrate how enmeshed language and learning problems are. It can be inferred that as children grow older, their language deficits are recognized in the context of a learning disorder. 
IMPLICATIONS

One inference from this study is that as children grow older, their language deficits are recognized in the context of a learning disorder. The clinical implications of this study include the importance of early intervention for speech and language impairments. Future research could include studies which demonstrate the efficacy of early intervention of SLI for preventing learning problems.

Although the relationship of SLI, LD, and ADHD is recognized, the implications of the relationship merit further study. One question which continues to need further exploration is whether ADHD is a cause or effect of SII and/or LD; whether the diagnoses coexist; or whether they are unrelated.

A reliable predictor of a learning disability is the split between the verbal and performance scores on a standardized instrument which measures IQ. Further analysis of the IQ data collected for this study may yield new insights into the relationship of language and learning disabilities.

For the SLP in the schools, this study affirms the need for membership on the MDT in making decisions about special education eligibility and placement. It also confirms the need for the SLP to be working as a consultant for students with learning problems that have a strong association with 
language development. 
American Psychiatric Association (1987). Diagnostic and statistical manual of mental disorders, $3 \mathrm{rd} \mathrm{Ed.-Revised.}$ Washington, D.C.: American Psychiatric Association.

American Speech-Language-Hearing Association (1991). Research Division. Rockville, MD.

Baker, L., \& Cantwell, D.P. (1987). Factors associated with the development of psychiatric illness in children with early speech/language problems. Journal of Autism and Developmental Disorders, 17, (4), 499-510.

Baker, L., Cantwell, D.P. \& Mattison, R.E. (1980). Behavior problems in children with pure speech disorders and in children with combined speech and language disorders. Journal of Abnormal Child Psychology, 8 , (2), 245-256.

Bloom, L., \& Lahey, M. (1978). Language development and language disorders. New York: John Wiley \& Sons, Inc.

Botelho, J. (1986). A comparison of behavioral problems between speech and/or lanquage impaired children and normal children. Unpublished master's thesis, Portland State University, Portland, OR.

Cantwell, D.P., \& Baker, L. (1977). Psychiatric disorder in children with speech and language retardation. Archives of General Psychiatry, 34, 583-590.

Cantwell, D.P., \& Baker, L. (1985). Psychiatric and learning disorders in children with speech and language disorders. Advances in learning and behavioral disabilities, 4, 29-47.

Cantwell, D.P., \& Baker, L. (1987). Prevalence and type of psychiatric disorder and developmental disorders in three speech-language groups. Journal of Communications Disorders, 20, 151-160.

Cantwell, D.P., \& Baker, L. (1991). Association between attention deficit-hyperactivity disorder and learning disorders. Journal of Learning Disabilities, 24, (2), 88-94. 
Cantwell, D.P., \& Satterfield, J.H. (1978). The prevalence of academic underachievement in hyperactive children. Journal of Pediatric Psychology, 3, (4), 168-171.

Catts, H.W. (1986). Speech production/phonological deficits in reading-disordered children. Journal of Learning Disabilities, 19, (8), 504-507.

Cunningham, C.D., \& Barkley, R.A. (1978). The role of academic failure in hyperactive behavior. Journal of Learning Disabilities, 2, (5), 15-21.

Digest of Education Statistics (1988). U.S. Department of Education.

Feagans, L., \& Appelbaum, M.I. (1986). Validation of language subtypes in learning disabled children. Journal of Educational Psychology, 78, (5), 358-364.

Gibbs, D.P. \& Cooper, E.B. (1989). Prevalence of communication disorders in students with learning disabilities. Journal of Learning Disabilities, 22, (1), 291-295.

Giddan, J.J. (1991). School children with emotional problems and communication deficits: Implications for speech-language pathologists. Language, Speech, and Hearing Services in Schools, 22, 291-295.

Goldstein, H.S. (1987). Cognitive development in inattentive, hyperactive, and aggressive children: Two to five-year follow-up. Journal of American Academy of Child and Adolescent Psychiatry, 26, 219-221.

Guevremont, D.C., DuPaul, G.J., \& Barkley, R.A. (1990). Diagnosis and assessment of attention deficithyperactivity disorder in children. Journal of Child Psychology, 28, 51-78.

Heward, W.L., \& Orlansky, M.D. (1988). Exceptional Children (3rd ed.). Columbus, OH: Merrill Publishing Company.

Jaeger, R.M. (1990). Statistics a spectator sport (2nd ed.). Newbury Park, CA: Sage Publications, Inc.

Keogh, B.K. (1971). Hyperactivity and learning disorders: REview and speculation. Exceptional Children, 38, 101109. 
Kuder, S.J. (1991). Language abilities and progress in a direct instruction reading program for students with learning disabilities. Journal of Learning Disabilities, 24, (2), 124-127.

Liberman, I.Y. \& Shankweiler, D. (1985). Phonology and the problems of learning to read and write. Remedial and Special Education, 6, (6), 8-17.

McGee, R., \& Share, D.L. (1988). Attention deficit disorder-hyperactivity and academic failure: Which comes first and what should be treated. Journal of the American Academy of Child and Adolescent Psychiatry, 27, (3), 318325 .

Meentz, C.K. (1989). Attention deficit disorder: A review of the literature. Psychology in the Schools, 26, 168178 .

Mercer, C.D., King-Sears, P., \& Mercer, A.R. (1990). Learning disabilities and criteria used by state education departments. Learning Disability Quarterly, 13, 141-152.

Reynolds, C.R., \& Fletcher-Janzen, E. (Eds.) (1990). Concise encyclopedia of special education. New York: John Wiley \& Sons, Inc.

Shafritz, J.M., Koeppe, R.P., \& Soper, E.W. (1988). The facts on file dictionary of education. New York: Facts on File.

Twaite, J.A., \& Monroe, J.A. (1979). Introductory statistics. Glenview, IL: Scott, Foresman and company.

University Affiliated Program. (1985). Learning Disorders Clinic, Trainee orientation Materials. Portland, OR: Child Development Rehabilitation Center.

van der Wissel, A. (1988). Hampered production of words as a characteristic of school failure. Journal of Learning Disabilities, 21, (8), 517-518.

Wallach, G.P., \& Liebergott, J.W. (1984). Who shall be called "learning disabled": Some new directions. In G.P. Wallach and K.G. Butler (Eds.), Language learning disabilities in school-aged children. Baltimore, MD: Williams \& Wilkins.

Wiig, E.H., \& Semel, E. (1984). Language assessment and intervention for the learning disabled. Columbus, $\mathrm{OH}$ : Charles E. Merrill Publishing Company. 


\section{APPENDIX A}

DSM-IIIR CRITERIA FOR DIAGNOSIS OF ADHD 
Diagnostic criteria for 314.01 Attention-deficit Hyperactivity Disorder

Note: Consider a criterion met only if the behavior is considerably more frequent than that of most people of the same mental age:

A. A disturbance of at least six months during which at least eight of the following are present:

(1) often fidgets with hands or fett or squirms in seat (in adolescents, may be limited to subjective feelings of restlessness)

(2) has difficulty remaining seated when required to do so

(3) is easily distracted by extraneous stimuli

(4) has difficulty awaiting turn in games or group situations

(5) often blurts out answers to questions before they have been completed

(6) has difficulty following through on instructions from others (not due to oppositional behavior or failure of comprehension), e.g., fails to finish chores

(7) has difficulty sustaining attention in tasks or play activities

(8) often shifts from one uncompleted activity to another

(9) has difficulty playing quietly

(10) often talks excessively

(11) often interrupts or intrudes on others, e.g., butts into other children's games

(12) often does not seem to listen to what is being said to him or her

(13) often loses things necessary for tasks or activities at school or at home (e.g., toys, pencils, books, assignments)

(14) often engages in physically dangerous activities without considering possible consequences (not for the purpose of thrili-seeking), e.g., runs into street without looking

Note: The above items are listed in descending order of discriminating power based on data from a national field trial of the DSM-IIIR criteria for Disruptive Behavior Disorders.

B. Onset before the age of seven

c. Does not meet the criteria for a Pervasive Developmental Disorder. 
Criteria for severity of Attention-deficit Hyperactivity Disorder:

Mild: Few, if any, symptoms in excess of those required to make the diagnosis and only minimal or no impairment in school and social functioning.

Moderate: Symptoms or functional impairment intermediate between "mild" and "severe."

severe: Many symptoms in excess of those required to make the diagnosis and significant and pervasive impairment in functioning at home and school and with peers. 
APPENDIX B

PATIENT POPULATION AT UAP OF OHSU

March, 1990 to February, 1991 
PATIENT POPULATION AT UAP OF OHSU

March, 1990 to February, 1991

\begin{tabular}{|c|c|c|}
\hline $\mathbf{A G E}$ & NOMBER & PERCENT \\
\hline $0-1$ (Years) & 283 & 3.8 \\
\hline $2-5$ & 2,287 & 30.4 \\
\hline $6-11$ & 1,988 & 26.4 \\
\hline $12-17$ & 1,126 & 14.9 \\
\hline $18-21$ & 479 & 6.4 \\
\hline $22-59$ & 1,341 & 17.8 \\
\hline $60+$ & 22 & .3 \\
\hline Unknown & 9 & .0 \\
\hline TOTAL & 7,535 & 100.8 \\
\hline GENDER & NUMBER & PERCENT \\
\hline Male & 3,713 & 49.3 \\
\hline Female & 3,822 & 50.7 \\
\hline TOTAL & 7,535 & $100 . \frac{8}{8}$ \\
\hline ETHNICITY & NOMBER & PERCENT \\
\hline White & 6,876 & 91.3 \\
\hline Hispanic & 237 & 3.1 \\
\hline Asian & 138 & 1.8 \\
\hline Black & 92 & 1.2 \\
\hline Native American & 82 & 1.1 \\
\hline other & 110 & 1.5 \\
\hline TOTAL & 7,535 & 100.8 \\
\hline
\end{tabular}




\section{APPENDIX C}

DEMOGRAPHIC DATA

\section{UAP/OHSU}

1990-1991 
DEMOGRAPHIC DATA

UAP/OHSU

1990-1991

\begin{tabular}{|c|c|}
\hline AGE & NOLBER \\
\hline $0-1$ (Years) & 77 \\
\hline $2-5$ & 1,276 \\
\hline $6-11$ & 929 \\
\hline $12-17$ & 535 \\
\hline $18-21$ & 42 \\
\hline $22-59$ & 289 \\
\hline $60+$ & 9 \\
\hline Unknown & 0 \\
\hline TOTAL & 3,157 \\
\hline ETHNICITY & NUMBER \\
\hline White & 2,737 \\
\hline Spanish/Hispanic & 228 \\
\hline Asian/Pacific Islander & 12 \\
\hline Black & 94 \\
\hline Native American & 86 \\
\hline other & 0 \\
\hline TOTAL & 3,157 \\
\hline BRIMARY IS/CONDITION & NOMBER \\
\hline $\begin{array}{l}\text { Mental Retardation } \\
\text { (cognit ive Belay) }\end{array}$ & 290 \\
\hline Autism & 500 \\
\hline Cerebral Palsy & 743 \\
\hline Communication Disorder & 152 \\
\hline Learning Disability & 50 \\
\hline Multiply Handicapped & 78 \\
\hline $\begin{array}{l}\text { Genetic Pisorders } \\
\text { Adult }\end{array}$ & 261 \\
\hline TOTAI & 2,074 \\
\hline
\end{tabular}




\section{APPENDIX D}

SELECTED ASSESSMENT MATERIALS USED BY LEARNING DISORDERS CLINIC 


\section{A. SPECIAL EDUCATION}

As part of the protocol for the Learning Disabilities Clinic, the special educator administer portions of the Woodcock-Johnson Psychoeducational Battery (WJPEB). The battery is composed of individually administered

standardized tests that measure both scholastic aptitude and academic achievement. The battery, normed for subjects from 3:0 to 80:0, is particularly useful in identifying and quantifying aptitude-achievement discrepancies. A significant aptitude-achievement discrepancy is part of the criteria that must be met in order for a student to qualify for special education services for a learning disability. The following sub-tests from the WJPEB are administered during Learning Disorders Clinic.

1. Tests of Aptitude

(a) Reading

(1) Visual Auditory Learning

(2) Blending

(3) Antonyms \& Synonyms

(4) Analogies

(b) Mathematics

(1) Visual Matching

(2) Antonyms \& Synonyms

(3) Analysis-synthesis

(4) Concept Formation

2. Tests of Achievement

(a) Reading

(1) Letter-Word Identification

(2) Word Attack

(3) Passage Comprehension

(b) Mathematics

(1) Calculation

(2) Applied Problems

\section{B. PSYCHOLOGY}

The following instruments are most frequently used by psychology in the Learning Disorders Clinic. However, the intern and faculty supervisor may decide to use other instruments which may be more helpful in answering the referral questions.

1. Measure of Intellectual Ability

a. Wechsler Intelligence Scale for children - 
Revised (WISC-R)
b. Stanford-Binet Intelligence Scale: Form L-M
c. Stanford-Binet Intelligence: Fourth Edition

2. Measures of Adaptive Behavior

a. Vineland Adaptive Behavior Scales

b. Adaptive Behavior Scales

3. Measure of Emotional, Personality Functions and Self-Esteem

a. Roberts Apperception Test

b. Harter Self-Esteem Scale

c. Piers-Harris Self-Esteem Inventory

d. Kovacs Child Depression Inventory

4. Measures of Behavior

a. Achenbach, Conners, Quay Behavior Checklist

b. Conners Check List

c. Eyberg Child Behavior Inventory

5. Behavior observations, interviews, with the child/parent/teachers.

C. SPEECH, LANGUAGE, \& HEARING

The following are frequently used measures of speech and language functioning in the Learning Disabilities clinic.

1. Token Test for Children - this measure is used to assess receptive language functioning in children. It is appropriate for ages 3 to $121 / 2$ years.

2. Peabody Picture Vocabulary Test - Revised (PPVTR) . This measure is used to assess receptive vocabulary and applies to ages $31 / 2$ through adult.

3. Expressive one-Word Picture Vocabulary Test (EOWPT). This instrument measures expressive vocabulary in 2:0 through 11:11 year old children.

4. Clinical Evaluation of Language Function - Revised (CELF-R). This test measures receptive-expressive language skills in school-aged children.

5. Photo Articulation Test (PAT). This test is used to map articulation errors in children's' speech. It is used only when a child is having articulation difficulties. 
6. Informal measures. Informal measures include a language sample, testing to see whether the child can follow complex commands with two, three, or four parts, sequencing activities presented both auditorially and visually, categories association, matching abilities, word and sentence imitation, and speech naming to assess word finding difficulties.

7. Other measures. Speech pathology also administers the Matching Familiar Figures Test (MFFT). This test is used to assess impulsive behaviors and the child's general ability to attend. The test measures both speed and accuracy in children ages 5 through 12 .

8. Audiometric screening. Children in the Learning Disabilities clinic are also provided with a standard hearing test. part of this test may include tympanometry which is used to assess middle ear functioning.

D. SOCIAL WORK

The following is an outline that social work uses in the Learning Disabilities clinic to structure the interview.

1. What do parent see as the problem?

a. Where will the problem go with time? (prognosis)

b. How do parents differ from each other in view of problem?

c. How do parents handle their differences?

d. How does the child see and deal with their difference?

2. What is the parent suspected cause of the problem? a. Genetic causation?

b. Psychological causation?

c. Parental guilt connected to suspected causes?

3. What have parents done about the problem? What works? What does not and why?

4. What is each parent's family of origins educational/learning experience?

5. What do extended family and other support systems think of this problem? On some occasions social work also uses the Faces-A Test of Family Cohesion 
by olsen, et al.

E. PEDIATRICS

The assessment tools used by pediatrics involve two major areas. The first is use of the medical and genetic history and a thorough physical and neurological examination. This is primarily to assess biological integrity. The second measure that is performed by pediatrics is the neuromaturational assessment. This area looks for soft signs of dysfunction as well as other deviations which may contribute to learning disabilities. The tools used are the Anser questionnaires, Connor hyperactivity forms, PEER, PEEX, and PEERAMID assessments developed at Harvard by Mel Levine, M.D. 


\section{APPENDIX E}

RESEARCH DATA FORM 


\section{RESEARCH DATA FORM}

DATE :

Project File No.

Meets Criteria:

Yes

No

CDRC Chart No.:

DOB :

Sex: $\mathbf{M}$

F

Gr:

Age at Time of Evaluation:

Reason for Referral:

Academic

Behavior

ADHD

Prior Speech/Language assessment and/or intervention? COMMENTS :

Health Factors:

FS IQ:

$\mathbf{V}:$

$\mathbf{P :}$

Audiological WNL:

LEARNING DISORDERS CLINIC FINDINGS:

SLI: Yes

No

Prior condition:

New Finding:

Type of Language Deficits:

LD: Yes No Prior condition:

New Finding:

Comments:

ADHD: Yes

No

Prior condition:

New Finding:

Medication: Yes No

Comments : 
APPENDIX $\mathbf{F}$

SUMMARY OF DATA 


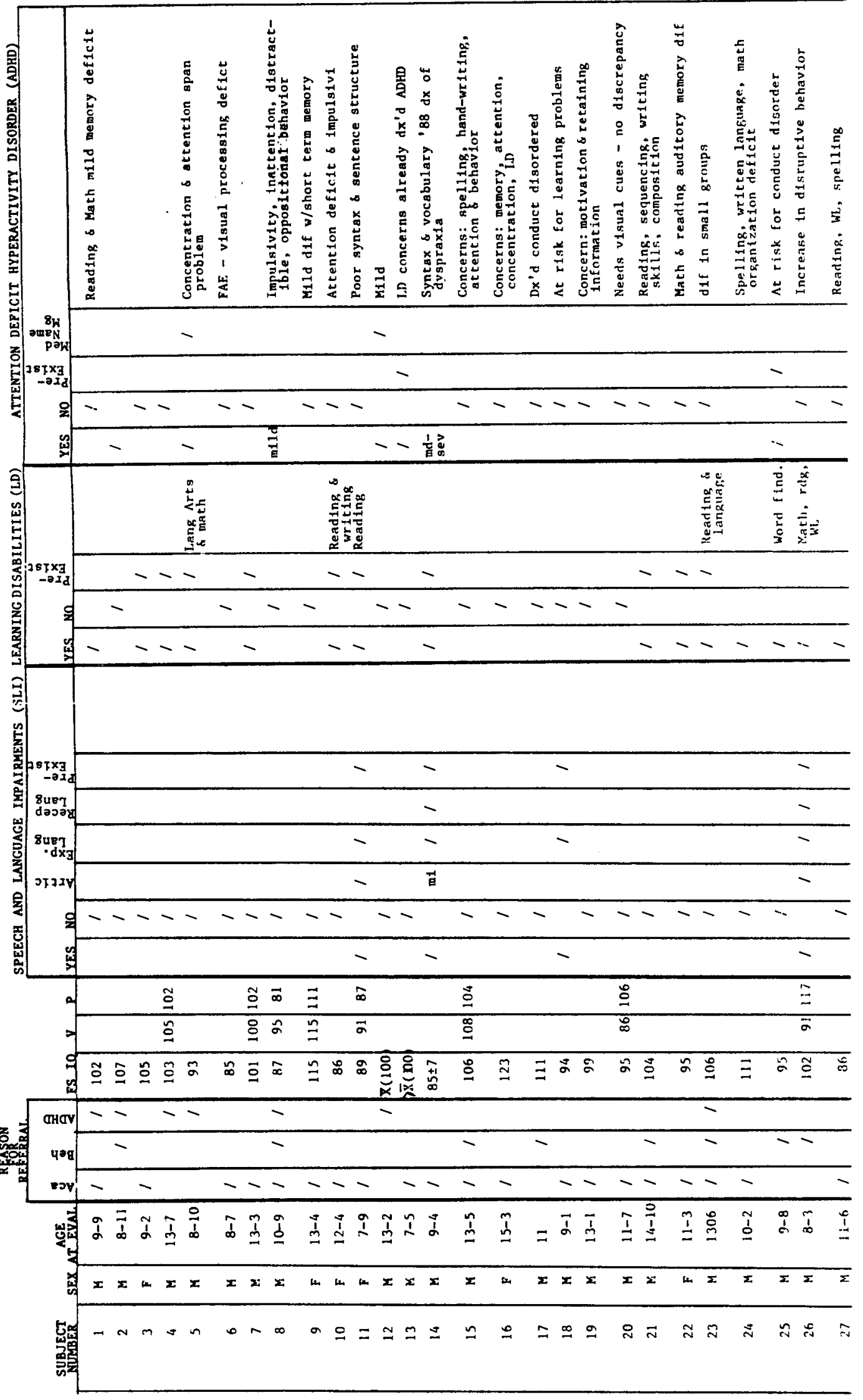




\begin{tabular}{|c|c|c|c|c|c|c|c|c|c|c|c|c|c|c|c|c|c|c|c|c|c|}
\hline 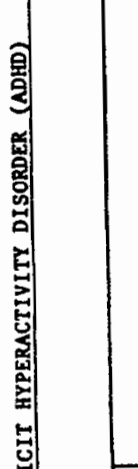 & 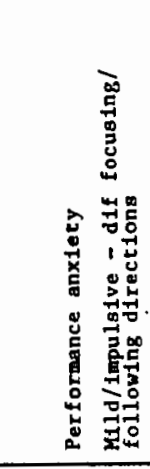 & 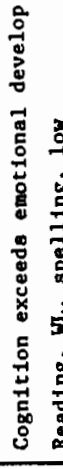 & 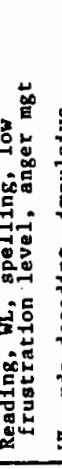 & 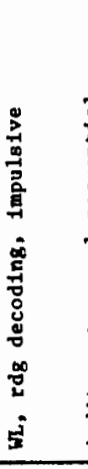 & 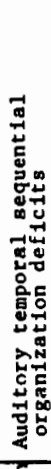 & 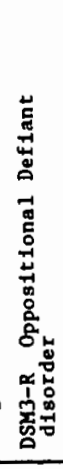 & 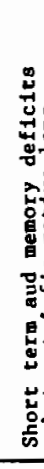 & & 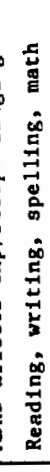 & & 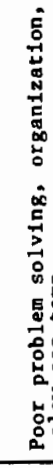 & 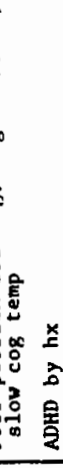 & & 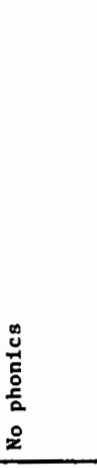 & 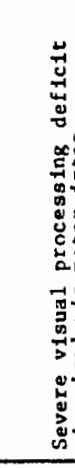 & 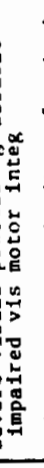 & 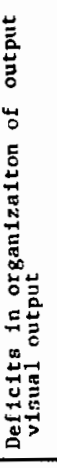 & 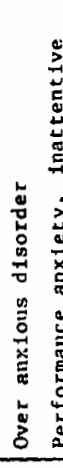 & 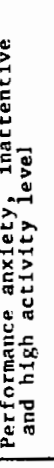 & 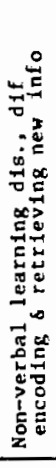 & 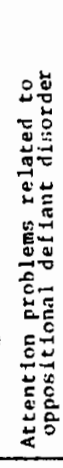 \\
\hline 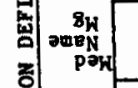 & & & & & 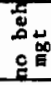 & & & & & & & & & & & & & & & & \\
\hline 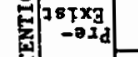 & & & - & & & - & & & & & & & & & & & & & & & \\
\hline 윤 & - & - & 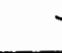 & - & & & - & 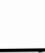 & - & & - & & & -- & -1 & & - & - & - & - & - \\
\hline 必 & - & & - & 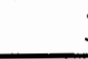 & E & - & & E & 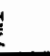 & & & & 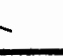 & & & & & & & & \\
\hline 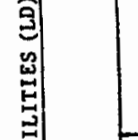 & & & & $\begin{array}{r}5 \\
5 \\
\end{array}$ & 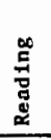 & & 这 & & 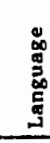 & & & 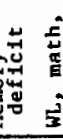 & 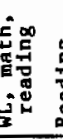 & 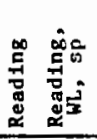 & & & 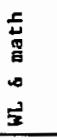 & & 5 & $\begin{array}{l}9 \\
\vdots \\
\vdots\end{array}$ & $\frac{E}{\vec{E}}$ \\
\hline 0 & & & - & & & & & & & & $=$ & $=$ & $=$ & - & & & & & & & \\
\hline 웣 & --1 & - & & & & - & . & - & - & & & & & & - & & & - & & & \\
\hline 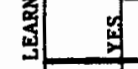 & & & - & -- & & & z & & - & & - & - & $=$ & $-\frac{0}{\frac{i}{y}}$ & $=$ & 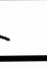 & $=$ & & $=$ & - & - \\
\hline 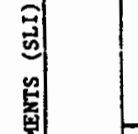 & & & & & 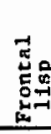 & & & & 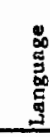 & & & & & & & & & & & & \\
\hline 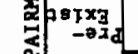 & & & & & & & & & & & & & - & & & & & - & & & \\
\hline $\begin{array}{l}=8087 \\
\text { dasoge }\end{array}$ & & & & & & & 尊 & & $=$ & & & & & & & & & - & & & - \\
\hline 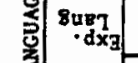 & & & & & & & 皃 & & & & & & $\infty$ & & - & & & & - & & - \\
\hline 3) & & & & & - & & & & & & & & & - & & & & & & & \\
\hline 9 & --- & -7 & 一 & - & & - & & - & - & & - - & & & - & - & - & - & & & - & \\
\hline s) & & & & & - & & $=$ & 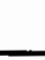 & - & & & & - & - & - & & & - & & & - \\
\hline & $\mathscr{\infty}$ & & $\Xi$ & 8. & & $\tilde{\Xi}$ & $\Xi$ & & 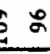 & & à & 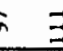 & $\Xi$ & $\stackrel{\circ}{\circ}$ & б ะ & & $\Xi$ & & $\stackrel{\Xi}{\Xi}$ & $\stackrel{\infty}{\infty}$ & \\
\hline & $\mathscr{2}$ & & $\stackrel{2}{\Xi}$ & $\Xi \stackrel{\infty}{\Xi}$ & $a$ & $\stackrel{\infty}{\Xi}$ & 8 & & $: 2$ & & $\stackrel{8}{8}$ & 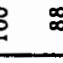 & . & $\underline{9}$ & $\infty \Xi$ & & $\cong$ & & $\begin{array}{l}\infty \\
\infty\end{array}$ & $\cong$ & \\
\hline 9 & $\infty \vec{\sigma}$ & $\stackrel{\alpha}{\alpha}$ & $\stackrel{\infty}{\Xi}$ & $\Xi \Xi$ & & $\cong$ & \& & 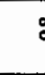 & 25 & & की & 2 & 2 & $\cong \cong$ & $\infty$ & & $\vec{\Xi}$ & & $\stackrel{\circ}{\circ}$ & $\stackrel{g}{0}$ & $\infty$ \\
\hline arov & & & & & - & & & & & & & & & & & & & & & & \\
\hline $4 \cdot 8$ & $-\cdots$ & - & - & - & - & - & - & 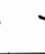 & - & & - & & & - & - & & - & - & & & - \\
\hline Evy & -2 & & & - & - & & $=$ & - & - & & - & - & - & - & - & & $=$ & & - & - & - \\
\hline 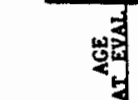 & $\approx \stackrel{0}{\stackrel{0}{2}}$ & - & I & $\tilde{d} \stackrel{0}{=}$ & $\hat{\mathfrak{s}}$ & $\hat{\vdots}$ & $i$ & . & $\stackrel{1}{\stackrel{1}{\leftrightarrows}}$ & & $\begin{array}{ll}\infty & \overrightarrow{1} \\
0 & 1 \\
0 & 1\end{array}$ & 7 & $\bar{I}$ & ปั & $\stackrel{i}{=} 0$ & 웅 & $\stackrel{0}{i}$ & $I ?$ & $\tilde{m}$ & $\simeq$ & $\infty$ \\
\hline 氙 & $=\infty$ & $x$ & $x$ & $x x$ & $x$ & $\Sigma$ & $x$ & 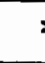 & $x=$ & & $x x$ & a & in & $x x$ & $\Sigma$ & & $\Sigma$ & $\Sigma$ & $x$ & $x$ & w \\
\hline 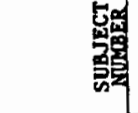 & $\stackrel{\infty}{\sim}$ i & $\vec{m}:$ & $\approx$ & in & $\approx$ & $\stackrel{\circ}{\circ}$ & f & : & 号 & & $8=$ & $F=$ & $\approx$ & 37 & $q 9$ & & $\hat{\sigma}$ & 舫 & $g$ & in & $\bar{n}$ \\
\hline
\end{tabular}




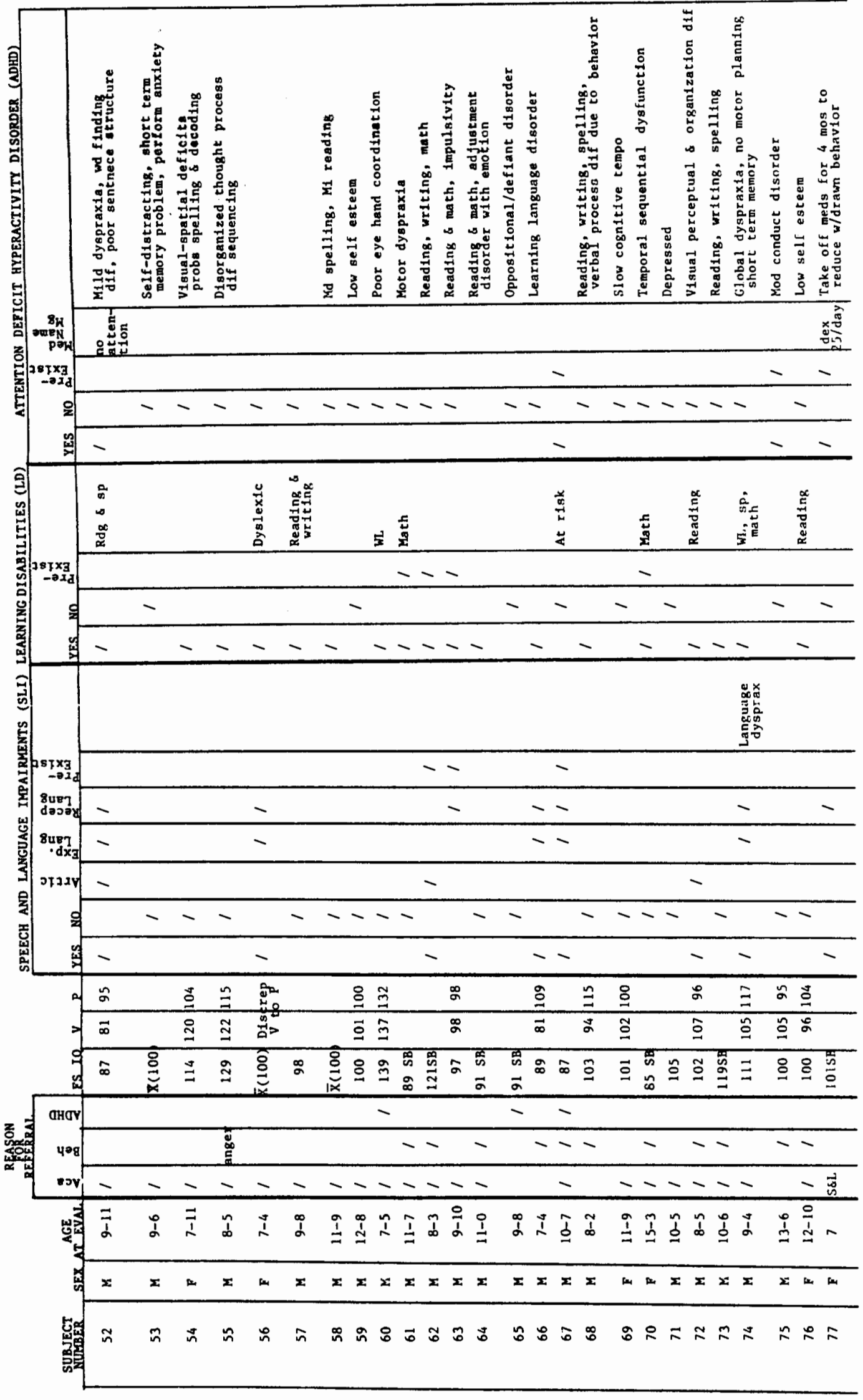




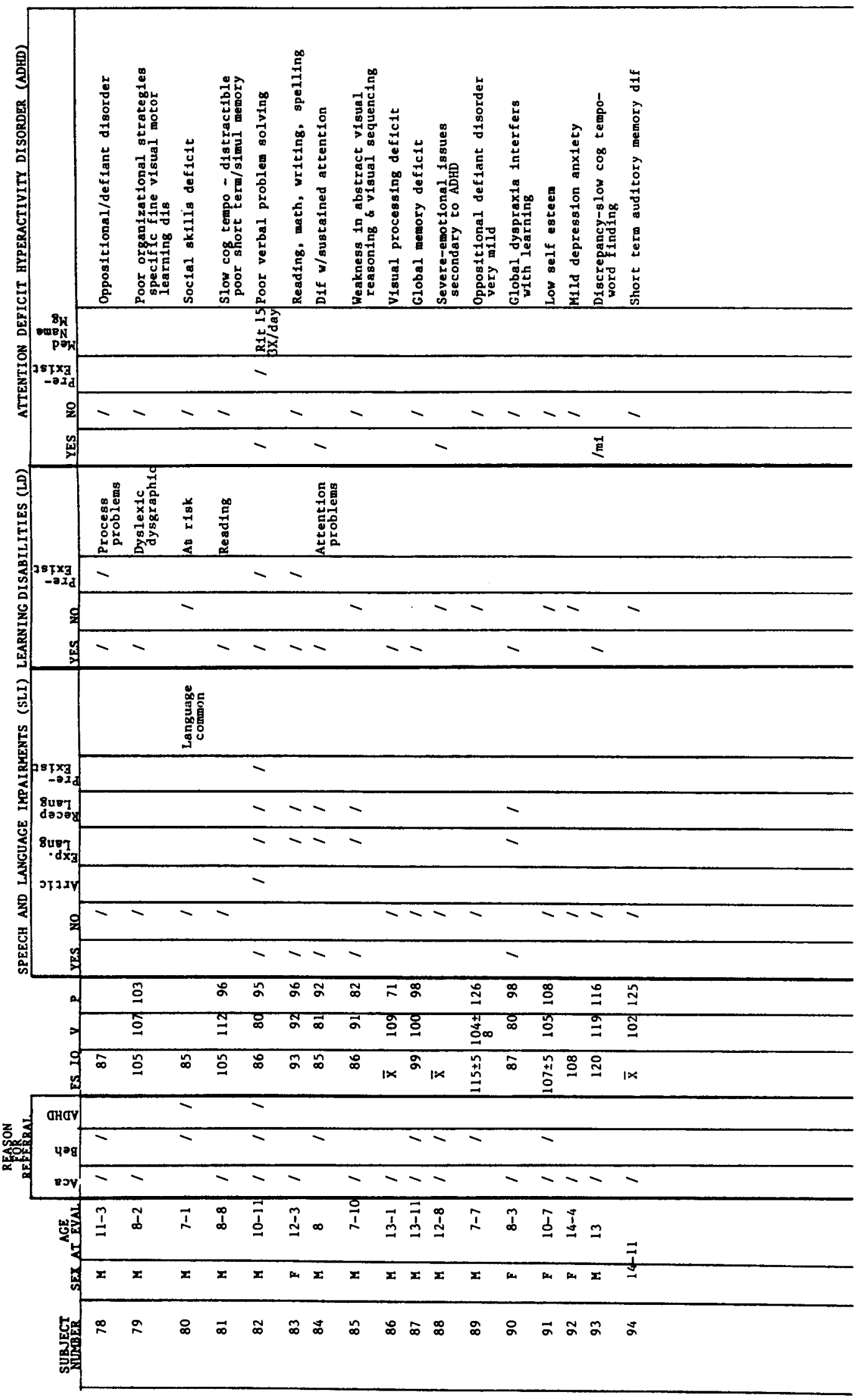




\section{APPENDIX G}

THE PERCENTAGES OF EXCLUSIONARY FACTORS

IN THE 197 REFERRALS NOT ELIGIBLE FOR THIS STUDY 
THE PERCENTAGES OF EXCLUSIONARY FACTORS

IN THE 197 REFERRALS NOT ELIGIBLE FOR THIS STUDY

1. File Incomplete:

2. IQ Less Than 85:

3. Not within Age Criteria (7 years to 15:11):

4. Hearing Not within Normal Limits:

5. Severely Emotionally Disturbed:

6. Other Health Impaired:

$$
\text { CP: } 2
$$$$
\text { Seizure Disorder: } 7
$$$$
\text { Traumatic Brain Injury (TBI): } 5
$$$$
\text { Premature Birth: } 3
$$

Severe Sexual Abuse: 6 other: 12

(35) $\quad 18 \%$

(15) $8 \%$

(13) 68

(48) 248

Total Males: 148 (75\%)

Total Females: 49 (25\%) 